\title{
Numerical evaluation of prestressed steel-concrete composite girders with external FRP or steel tendons
}

\author{
Tiejiong Lou ${ }^{* 1,2}$ and Theodore L. Karavasilis ${ }^{3}$ \\ 1. Hubei Key Laboratory of Roadway Bridge \& Structure Engineering, Wuhan University of \\ Technology, 430070 Wuhan, China \\ 2. Faculty of Engineering and Physical Sciences, University of Southampton, SO17 1BJ Southampton, \\ United Kingdom \\ 3. Department of Civil Engineering, University of Patras, GR-26500 Patras, Greece
}

\begin{abstract}
The use of external FRP tendons instead of steel ones for prestressing steel-concrete composite girders is evaluated. A nonlinear model for prestressed steel-concrete composite (PSCC) girders is calibrated against experimental results. Numerical simulations are then performed on singe-span and two-span PSCC girders. The investigated variables are the tendon type and the prestress level. In particular, CFRP, AFRP and conventional prestressing steel tendons are compared for prestress levels ranging from 0 to $60 \%$. The results demonstrate that the behavior of PSCC girders with CFRP and steel tendons is similar, while AFRP tendons result in lower ultimate load and higher deformation capacity. In addition, the influence of prestress level on the moment at the center support of continuous PSCC girders is marginal due to the presence of secondary moments. The study also shows that the influence of secondary moments on moment redistribution is less pronounced in PSCC girders with AFRP tendons than in PSCC girders with CFRP or steel tendons.
\end{abstract}

Keywords: Composite girder; FRP tendon; Prestress level; Behavior

\footnotetext{
* Corresponding author.

E-mail address: T.Lou@soton.ac.uk (T. Lou).
} 


\section{Introduction}

Steel-concrete composite girder bridges are widespread in Europe and worldwide. In these bridges, the composite action is commonly achieved by shear studs, which are welded on the steel beam and are embedded in the concrete slab. Despite their attractive advantages such as high stiffness and load-carrying capacity, these bridges experience high stress level in the tension face of the steel beam. Moreover, the concrete slab over negative moment regions may suffer excessive cracking. The application of external prestressing is considered as an effective way to address the afore-mentioned issues [1-3]. In particular, external prestressing increases the ultimate load-carrying capacity, reduces the service-load deformation and stress in structural steel, and enhances the resistance against concrete cracking [1-3].

Extensive studies have been carried out on prestressed steel-concrete composite (PSCC) members. Various mathematical models for nonlinear analysis of PSCC members have been developed by different investigators [4-8]. Many experimental, numerical and analytical works were performed for evaluating the structural response of simply supported PSCC members under positive bending [1,9-15]. Results related to flexural behavior of such members under negative bending were also reported $[2,3,16]$. Researchers also focused on the performance of continuous PSCC members [17-20]. A few works studied the issue of moment redistribution in such members $[18,19]$. The secondary moment for statically indeterminate PSCC members may be significant but relevant research is scarce [20]

All the above-mentioned studies on PSCC members focused on steel tendons, 
which are naturally susceptible to corrosion. To minimize the corrosion problem the steel tendons are commonly wrapped with grease-filled plastic sheaths. This protection technique, however, will increase the cost and also add the difficulty in inspecting the tendons. The most efficient way to address the corrosion issue is to use tendons made of fiber reinforced polymer (FRP) composites. These composite materials, characterized by non-corrosive property and high strength-weight ratio, are gaining popularity for structural rehabilitation [21-30]. Typical composite tendons include aramid (AFRP) and carbon (CFRP) ones, which exhibit favorable creep performance [31]. Grass fibers, in general, are not suitable for prestressing tendons because of creep rupture under a low sustained load level. Both AFRP and CFRP tendons possess high tensile strength, comparable to that of prestressing steel tendons. AFRP tendons show substantially lower elastic modulus than steel tendons. The CFRP modulus of elasticity covers a large range, varying between 0.4 and 2.5 times the steel one. The relaxation of AFRP tendons is considerably more pronounced than that of steel tendons, while CFRP tendons exhibit superior relaxation resistance, comparable to or even better than low-relaxation prestressing steel [31]. Although the initial cost of FRP (especially CFRP) is higher than that of steel, the life span of FRP-strengthened systems may be cost-effective because of the superior characteristics of FRP materials. A major concern on the use of FRP tendons is related to anchorages, which are rather sophisticated and need to be specially designed. Common anchorages for steel tendons are not applicable to FRP tendons. Extensive works have been conducted to develop strong anchorage systems for FRP tendons 
Many studies [33-37] on steel-concrete composite or steel members strengthened by prestressing FRP sheets/plates have been carried out. The retrofit effectiveness of using such FRP-prestressing technique was demonstrated in these studies. When FRP tendons are adopted instead of conventional steel ones, some challenges on the design of PSCC members may arise due to the non-standard mechanical properties of the FRP material. The response of concrete members with FRP tendons has been broadly addressed [38-40]. However, the results obtained from these studies may not be valid for steel-concrete composite members due to the pronounced difference between the two structural systems. Therefore, the use of external FRP tendons for strengthening steel-concrete composite members needs to be further investigated.

This paper presents a comparative study between PSCC girders with external FRP or steel tendons. A nonlinear model for such girders is calibrated against experimental results. Numerical simulations of single-span and two-span PSCC girders with steel, CFRP and AFRP tendons at different prestress levels (i.e. from 0 to $60 \%$ ) are then carried out. With respect to continuous PSCC girders, emphasis is given on evaluating the effect of secondary moments and moment redistribution.

\section{Nonlinear model and its validation}

\subsection{Nonlinear model}

A numerical model for PSCC girders has been developed [7]. The following assumptions are adopted: composite sections remain plane after bending; shear 
deformations are considered negligible compared to flexural ones; and no slip between the steel beam and the concrete slab takes place. The latter assumption is considered to be reasonable when sufficient shear studs are provided along the girder. For partial interaction between the steel beam and the concrete slab, this assumption, however, would lead to stiffer structural behavior and an overestimate of the ultimate load. Although the modeling of time-dependent effects is not covered in this study, it is worth mentioning that despite insignificant relaxation, CFRP tendons with a high modulus of elasticity could experience a substantial long-term prestress loss due to creep and shrinkage of concrete. On the other hand, AFRP tendons would exhibit a significantly higher prestress loss contributed from tendon relaxation but a lower prestress loss contributed from concrete creep and shrinkage as a result of a lower modulus of elasticity, when compared to steel tendons.

Fig. 1 displays a beam element having nodal displacements

$$
\begin{gathered}
\boldsymbol{r}^{e}=\left\{\begin{array}{lll}
\boldsymbol{u}^{T} & \boldsymbol{v}^{T} & \boldsymbol{\theta}^{T}
\end{array}\right\}^{T} \\
\boldsymbol{u}=\left\{\begin{array}{ll}
u_{i} & u_{j}
\end{array}\right\}^{T}, \quad \boldsymbol{v}=\left\{\begin{array}{ll}
v_{i} & v_{j}
\end{array}\right\}^{T}, \quad \boldsymbol{\theta}=\left\{\begin{array}{ll}
\theta_{i} & \theta_{j}
\end{array}\right\}^{T}
\end{gathered}
$$

where $\boldsymbol{u}$ represents nodal axial displacements; $\boldsymbol{v}$ nodal transverse displacements; and $\boldsymbol{\theta}$ nodal rotations related to the local $x-y$ coordinate system. The axial displacement $u$ and transverse displacement $v$ can be expressed by [7]

$$
\begin{gathered}
u=\boldsymbol{N}_{1} \boldsymbol{u}, v=\boldsymbol{N}_{2}\left\{\begin{array}{ll}
\boldsymbol{v}^{T} & \boldsymbol{\theta}^{T}
\end{array}\right\}^{T} \\
\boldsymbol{N}_{1}=\left[1-\frac{x}{l} \frac{x}{l}\right], \quad \boldsymbol{N}_{2}=\left[1-\frac{3 x^{2}}{l^{2}}+\frac{2 x^{3}}{l^{3}} \frac{3 x^{2}}{l^{2}}-\frac{2 x^{3}}{l^{3}} \quad x-\frac{2 x^{2}}{l}+\frac{x^{3}}{l^{2}}-\frac{x^{2}}{l}+\frac{x^{3}}{l^{2}}\right]
\end{gathered}
$$

where $l$ represents the element length.

The axial strain is expressed as 


$$
\varepsilon=\frac{d u}{d x}+\frac{1}{2}\left(\frac{d v}{d x}\right)^{2}-y \frac{d^{2} v}{d x^{2}}
$$

By utilizing Eqs. (1)-(5), the strain-displacement equation is written as

$$
\varepsilon=\boldsymbol{B} \boldsymbol{r}^{e}+\frac{1}{2} \boldsymbol{r}^{e T} \boldsymbol{J}^{T} \boldsymbol{J} \boldsymbol{r}^{e}
$$

where

$$
\boldsymbol{B}=\left[\begin{array}{ll}
\frac{d \boldsymbol{N}_{1}}{d x} & -y \frac{d^{2} \boldsymbol{N}_{2}}{d x^{2}}
\end{array}\right], \quad \boldsymbol{J}=\left[\begin{array}{lll}
0 & 0 & \frac{d \boldsymbol{N}_{2}}{d x}
\end{array}\right]
$$

By applying the principle of virtual work, the element tangential governing equations are expressed as follows [7]:

$$
\begin{gathered}
d \boldsymbol{R}^{e}=\left(\boldsymbol{K}_{o}^{e}+\boldsymbol{K}_{g}^{e}\right) d \boldsymbol{r}^{e} \\
\boldsymbol{K}_{o}^{e}=\int_{V} \boldsymbol{B}^{T} E \boldsymbol{B} d V, \quad \boldsymbol{K}_{g}^{e}=\int_{V} \sigma \boldsymbol{J}^{T} \boldsymbol{J} d V
\end{gathered}
$$

where $\boldsymbol{R}^{e}$ represents the element equivalent nodal loads; $E$ the tangential modulus; $\sigma$ the stress; and $V$ the element volume. The effect of external tendons on the response of PSCC girders is expressed by equivalent loads. A detailed formulation of the numerical procedure can be found in [7].

The material laws implemented in the numerical formulation are as follows. The behavior of compressive concrete is simulated by the Hognestad [41] model. The stress-strain curve comprises parabolic ascending and linear descending branches (Fig. 2(a)). The tensile concrete is elastic and tension-stiffening (Fig. 2(b)). The behavior of steel tendons is simulated by the Menegotto and Pinto [42] model while the FRP tendons are linearly elastic (Fig. 2(c)). Both the steel beam and reinforcing bars are elastic-fully plastic (Fig. 2(d)). In Fig. 2, $\sigma_{c}$ is the concrete stress; $\varepsilon_{c}$ the concrete strain; $\varepsilon_{0}$ the concrete strain at peak stress; $f_{c}^{\prime}$ the concrete cylinder compressive 
strength; $f_{t}$ the concrete tensile strength; $\varepsilon_{c r}$ the cracking strain; $E_{c}$ the concrete elastic modulus; $\sigma_{p}$ the tendon stress; $\varepsilon_{p}$ the tendon strain; $f_{p u}$ the tendon ultimate strength; $E_{p}$ the tendon elastic modulus; $\sigma_{s}$ the steel stress; $\varepsilon_{s}$ the steel strain; $f_{y}$ the steel yield strength; $E_{s}$ the steel elastic modulus. Collapse of the girder is assumed to take place when any constituent material reaches its ultimate strain capacity. The proposed analysis consists of a load-control analysis during the prestressing phase and a displacement-control analysis for tracing the equilibrium path under external loads up to collapse.

\subsection{Comparison with experimental data}

\subsubsection{Simply supported PSCC beam specimen}

A simply supported PSCC beam specimen is used for calibrating the proposed model. The beam was tested by Ayyub et al. [1]. The specimen was posttensioned with two seven-wire straight strands placed $30.5 \mathrm{~mm}$ above the bottom flange (see Fig. 3). The area and initial prestressing force of steel tendons were $279 \mathrm{~mm}^{2}$ and $289 \mathrm{kN}$, respectively. Mechanical properties of materials are given in Table 1.

The model predictions are compared to the experimental data as well as to the analytical results by Ayyub et al. [1] in Fig. 3. The complete load-deflection curve predicted by the proposed model corresponds well with both the experimental and analytical results. The predicted increases in tendon force by Ayyub et al. and the proposed model are in excellent agreement during loading although the response curve by Ayyub et al. seems to be incomplete. The predicted force in external tendons tends to be higher than the experimental one, possibly due to the neglect of anchorage 
losses in the numerical procedure.

\subsubsection{Continuous PSCC beam specimen}

A two-span continuous PSCC beam specimen is also adopted for model validation. The beam was tested by Nie et al. [6,17]. The specimen was posttensioned with two steel strands and two deviators within each span and one deviator at the center support (see Fig. 4). The area and initial prestressing force of steel tendons were $278 \mathrm{~mm}^{2}$ and $246.4 \mathrm{kN}$, respectively. Material properties of concrete, steel beam and steel tendons are presented in Table 1. It should be noted that the mechanical properties of steel tendons were not given in $[6,17]$. Grade $270(1860 \mathrm{MPa})$ strands are assumed in the analysis.

Comparisons of numerical and experimental results are provided in Fig. 4. The nonlinear model traces satisfactorily the behavior at different levels of initial loading. However, the analysis overestimates the ultimate tendon force and load-carrying capacity. This may be attributed to the neglect of friction losses between external tendons and deviators.

\section{Behavior of simply supported PSCC girders}

Single-span PSCC girders (Fig. 5) are used in the first phase of the investigation. The girders are $12.0 \mathrm{~m}$ in span length and are subjected to two concentrated loads. The distance between the two point loads is $3.0 \mathrm{~m}$. Deviators are used at third points. The distances between the centroid of external tendons and the steel bottom flange are 295 and $45 \mathrm{~mm}$ at the support and deviator points, respectively. The external tendons 
are made of AFRP, CFRP or prestressing steel having $E_{p}$ of 50,150 or $195 \mathrm{GPa}$, respectively. The FRP and steel tendons are assumed to have an $f_{p u}$ equal to 1860 $\mathrm{MPa}$. The initial prestress level, $\sigma_{p 0} / f_{p u}$, varies from $0 \%$ to $60 \%$. The tendon area is $20 \mathrm{~cm}^{2}$. The area of the top or bottom steel rebars is $7.5 \mathrm{~cm}^{2}$, with $f_{y}$ and $E_{s}$ equal to $420 \mathrm{MPa}$ and $200 \mathrm{GPa}$, respectively. The values of $f_{y}$ and $E_{s}$ of the steel beam are $275 \mathrm{MPa}$ and $200 \mathrm{GPa}$, respectively. For the concrete, the values of $f_{c}^{\prime}, f_{t}$, and $E_{c}$ are $40 \mathrm{MPa}, 3.5 \mathrm{MPa}$ and $35 \mathrm{GPa}$, respectively.

\subsection{Load-deformation behavior}

Fig. 6(a) and (b) illustrate the effect of tendon type and prestress level on the load-deformation behavior of PSCC girders. The girders exhibit linear-elastic behavior up to yielding of the steel beam, followed by a significant reduction in flexural stiffness. In the elastic stage, the increase in the stress of external tendons is small, and therefore, the tendon type has negligible influence on the elastic response characteristics. After yielding of the steel beam, AFRP tendons result in substantially lower flexural stiffness than CFRP or steel ones because of their significantly lower $E_{p}$. The post-yielding behavior of CFRP and steel PSCC girders is similar, with small discrepancies attributed to the difference between their moduli of elasticity. As expected, the prestress level significantly influences the structural behavior, i.e. a higher prestress level leads to much stiffer behavior and higher yield and ultimate loads (or moments).

The variations of the ultimate load and deflection against the prestess level for AFRP, CFRP and steel tendons are illustrated in Fig. 6(c) and (d), respectively. 
Increasing the prestress level from 0 to $60 \%$ results in an increase in the ultimate load by $27.2 \%, 32.9 \%$ and $42.9 \%$ for steel, CFRP and AFRP tendons, respectively. Moreover, it leads to a decrease in the ultimate deflection by $14.6 \%, 16.6 \%$ and $16.1 \%$ for steel, CFRP and AFRP tendons, respectively. CFRP tendons show slightly lower ultimate load and higher ultimate deflection than steel ones. Replacing steel tendons with AFRP ones results in decreases in the ultimate load by $7.41 \%$ (for $60 \%$ prestress level) to $17.6 \%$ (for $0 \%$ prestress level), and an increase in the ultimate deflection by $7.0 \%$.

\subsection{Stress increase in external tendons}

Fig. 7(a) illustrates the effect of tendon type and prestress level on the relation between load and tendon stress increase. Since the prestress loss due to elastic compression is smaller for a lower tendon modulus of elasticity, the effective prestress in AFRP tendons is generally higher that that in CFRP or steel tendons. The tendon stress development consists of two distinct stages separated by yielding of the steel beam. In the first stage, the stress increases slowly, while the load increases rapidly. In the second stage, a significant tendon stress increment and a limited increase in the load are observed. The stress increases in CFRP and steel tendons are very similar over the entire loading process. The stress increase in GFRP tendons is significantly slower than that in steel tendons due to a significantly lower $E_{p}$.

Fig. 7(b) shows the variation of the stress increment at ultimate of external steel, CFRP and AFRP tendons with the prestress level. The ultimate stress increments of CFRP and AFRP tendons slightly decrease, in approximately a linear manner, with an 
increasing prestress level. For steel tendons, the ultimate stress increment decreases slightly as the prestress level increases up to $40 \%$, and thereafter a high prestress level results in a substantially lower stress increment at ultimate. This can be attributed to the fact that at ultimate, the steel tendons are approximately within the elastic range for a low prestress level, while they exhibit a notable nonlinearity for a prestress level greater than $40 \%$. The ratio of the ultimate tendon increment of AFRP tendons to that of CFRP tendons is 0.36 , which is a slightly higher than the elastic modulus ratio of 0.33. This can be explained by that fact that at ultimate AFRP tendons develop higher strain than CFRP tendons. The ratio of the ultimate stress increment of FRP tendons to that of steel tendons is also related to the elastic modulus ratio in the same way if the steel tendons are within their elastic range.

\subsection{Neutral axis depth}

Fig. 8(a) shows the effect of tendon type and prestress level on the load versus neutral axis depth curve of the PSCC girders. When a PSCC girder is subjected to its self-weight load only, the initial neutral axis depth depends on the prestress level. For zero prestress level, the initial neutral axis is located at the centroidal axis of the composite section. For a prestress level of $20 \%, 40 \%$ or $60 \%$, the initial neutral axis is located above the centroidal axis. As the applied load increases, the neutral axis depth for zero prestress level remains almost unchanged until yielding of the steel beam, and quickly decreases thereafter. For a prestress level of $20 \%, 40 \%$ or $60 \%$, the neutral axis depth decreases rapidly from a positive value to negative infinity at which the hogging curvature vanishes. At the beginning of sagging curvature, the neutral axis 
depth jumps suddenly from negative infinity to positive infinity. Thereafter, the neutral axis depth shows a rapid decrease with increasing load until crack development in the concrete slab stabilizes. Then the movement of the neutral axis gradually slows down up to yielding of the steel beam, followed by a quick decrease in its depth up to ultimate. Prior to yielding of the steel beam, changes in the neutral axis depth for different tendon types are similar. After yielding, AFRP tendons result in a much quicker decrease in the neutral axis depth with increasing load compared to CFRP or steel tendons.

Fig. 8(b) shows that at failure, the neutral axis depth increases as the prestress level increases. At specific prestress levels, the neutral axis depths for CFRP and steel tendons are almost identical. AFRP tendons lead to smaller neutral axis depth than steel ones. The difference is particularly notable at zero prestress level.

\subsection{Stresses and strains in reinforcing steel bars and steel beam}

Fig. 9 illustrates the development of strains and stresses in reinforcing bars for different tendon types and various prestress levels. Compressive strains or stresses in both the top and bottom bars increase slowly until yielding of the steel beam. Afterwards, the strain or stress in top bars increases quickly, while the compressive strain or stress in bottom bars gradually vanishes and then the tensile strain or stress occurs. The strain or stress developments in reinforcing bars for different types of tendons differ after the steel beam yields. AFRP tendons lead to faster increase of bar strain or stress than CFRP or steel tendons. At failure, all the top bars have slightly yielded, while all the bottom bars are far below their yield strength. AFRP tendons 
lead to a higher ultimate strain or stress in bottom bars than CFRP or steel tendons. The higher the prestress level, the lower the ultimate strain or stress in bottom bars.

The effect of tendon type and prestress level on the development of strain and stress in the steel beam is illustrated in Fig. 10. The strain and stress in the bottom flange increase linearly with increasing load until yielding. Afterwards, the increase in strain becomes faster. The strain and stress in the top flange are nearly unchanged until yielding of the extreme tension face and develop quickly afterwards. AFRP tendons lead to a faster increase in post-yielding strain in the steel beam than CFRP or steel tendons. The type of external tendons has practically no influence on the bottom flange stress development. At failure, the top flange does not reach its yield strength. AFRP tendons result in higher ultimate stress in the top flange than CFRP or steel tendons. The higher the prestress level, the lower the ultimate stress in the top flange.

\section{Behavior of continuous PSCC girders}

Two-span continuous PSCC girders with a total length of $24.0 \mathrm{~m}$ and under center-point loads at each span, as shown in Fig. 11, are used in the second phase of the investigation. The distances between the centroid of external tendons and the steel bottom flange are 295, 545 and $45 \mathrm{~mm}$ at outer, inner supports and midspan, respectively. All the other parameters are identical to those of the simply supported girders described in Section 3. The tendon type and prestress level influencing the behavior of continuous PSCC girders was found similar to that of simply supported ones. Therefore, this section presents only results relevant to the effect of secondary 
moments and moment redistribution of continuous PSCC girders.

\subsection{Secondary moment}

The magnitude of secondary moments in statically indeterminate PSCC girders could be very high as the tendon line in these girders is commonly located far away from the concordant line. The secondary moment varies significantly with the shift of the tendon line. It has been proved that tendon shift with linear transformation has no effects regarding full-range behavior of continuous prestressed girders [20,39]. By utilizing linear transformation, an approach for quantifying secondary moments was proposed in [20,39], i.e.: locate the position of linear-transformation concordant tendon line; compute bending moments for non-concordant and concordant tendon lines; calculate the secondary moment by subtracting the moment of the concordant tendon line from the moment of the non-concordant tendon line.

Fig. 12(a) shows the effect of tendon type and prestress level on the load versus secondary moment curves of the PSCC girders. It is noted that at the initial state, significant secondary moments could be existent. For instance, at $60 \%$ prestress level, the initial secondary moments at the center support for AFRP, CFRP and steel tendons are $977.1,950.6$ and $935.8 \mathrm{kN} \cdot \mathrm{m}$, respectively. The secondary moment develops slowly before yielding of the steel beam, and thereafter, a rapid increase is observed. The secondary moment development for AFRP tendons is slower than that for CFRP or steel tendons due to slower increase in tendon stress. At failure, the secondary moment and its distribution are illustrated in Figs. 12(b) and (c), respectively. An approximate linear relation between the secondary moment and the prestress level can 
be observed. AFRP tendons lead to smaller secondary moment than CFRP or steel tendons, and that difference is particularly notable at a low prestress level.

\subsection{Moment redistribution}

Fig. 13(a)-(c) show the effect of prestress level on the distribution of ultimate moments for steel, CFRP and AFRP tendons, respectively. The higher the prestress level, the larger the midspan moment at ultimate. However, the ultimate moments at the center support for different prestress levels are almost identical. The above observation is attributed to the influence of secondary moments. As can be seen in Fig. 12 , there are positive secondary moments over the span, which counteract the center support moment and enhance the midspan moment. In addition, a higher prestress level produces significantly higher secondary moments, which lead to a larger reduction in the center support moment and a larger increment in the midspan moment. Therefore, it is concluded that if the secondary moments are minimized by using a concordant tendon profile, a high prestress level would cause higher center support moment, but the difference of the midspan moments for different prestress levels would be less pronounced. For a given tendon type, the deviations between actual and elastic moments at the center support for different prestress levels are almost identical, indicating negligible influence of prestress level on moment redistribution.

Fig. 14 shows the load-moment curves for different types of external tendons. The dashed lines represent the development of elastic moments. The results are produced for $60 \%$ prestress level and by considering and neglecting secondary moments. These 
graphs clearly demonstrate how the secondary moments influence the moment development and how the actual moments $(M)$ differ relative to the elastic moments $\left(M_{e}\right)$ during the loading process. It is seen that the secondary moment substantially reduces the center support moment but increases the midspan moment. The actual moment starts to differ from the elastic moment at the cracking load due to redistribution of moments. The difference tends to be more pronounced as the load increases.

Fig. 15 shows the load versus degree of moment redistribution $\left(\beta=1-M / M_{e}\right)$ curves for the PSCC girders. A higher prestress level causes a larger cracking load at which moment redistribution initiates. At any inelastic load level, the presence of secondary moments results in an increase in moment redistribution over the center support and this observation becomes more apparent at high load levels. The influence of secondary moments on moment redistribution over the midspan is not as important as that over the center support. The secondary moment may increase or reduce the moment redistribution at the midspan during loading, depending on the load and prestress levels.

Fig. 16 illustrates moment redistribution variations with varying prestress level for different tendon types. When secondary moments are considered, the influence of prestress level on moment redistribution over the center support appears to be insignificant, while a higher prestress level results in substantially lower redistribution of moments at the midspan. In addition, AFRP and CFRP tendons lead to substantially and slightly lower redistribution values, respectively, when compared to steel tendons. 
When secondary moments are neglected, the moment redistribution at the critical sections decreases as the prestress level increases. In this case, AFRP tendons result in higher moment redistribution than CFRP or steel tendons. Over the center support, the secondary moment considerably increases the degree of redistribution, especially for high prestress levels. AFRP tendons exhibit less pronounced influence of secondary moments on moment redistribution compared to CFRP or steel tendons. At the midspan, the presence of secondary moments leads to an increase in the decrease rate of moment redistribution with increasing prestress level. In other words, the prestress level affecting moment redistribution at the midspan is mitigated when neglecting secondary moments.

\section{Conclusions}

Based on a numerical assessment of the behavior of single-span and two-span PSCC girders with different tendon types (AFRP, CFRP and steel) and prestress levels (from 0 to $60 \%$ ), the following conclusions are drawn:

- The behavior of PSCC girders with CFRP tendons is similar to that of PSCC girders with steel tendons. It is therefore feasible to replace steel tendons with CFRP ones without compromising the structural performance.

- Replacing steel tendons with AFRP ones leads to a substantial decrease in ultimate load and an increase in deformation capacity. Moreover, AFRP tendons result in smaller neutral axis depth and higher strains in the steel beam than steel tendons. 
- The increase in ultimate load with increasing prestress level is more effective for AFRP tendons than for CFRP or steel tendons. Therefore, using AFRP tendons at a high prestress level while CFRP tendons at a low prestress level may be recommended by considering both the cost and performance factors.

- For continuous PSCC girders, the prestress level significantly influences the midspan moment but hardly influences the center support moment due to the effect of secondary moments.

- The presence of secondary moments results in substantial increases in moment redistribution over the center support, while its influence on moment redistribution over the midspan is not important.

- The effect of secondary moments on moment redistribution for AFRP tendons is substantially less important than that for CFRP or steel tendons. AFRP tendons result in lower moment redistribution than CFRP or steel ones when considering secondary moments. Minimizing the secondary moments leads to the opposite observation.

- The effect of prestress level on moment redistribution over the center support is not important when considering secondary moments. If secondary moments are minimized, this effect becomes rather important. Moreover, minimizing the secondary moments reduces the prestress level influence on moment redistribution over the midspan.

\section{Acknowledgments}


The work has been supported by the European Union's Horizon 2020 research and innovation program under the Marie Sklodowska-Curie grant agreement No. 751921 and by the Fundamental Research Funds for the Central Universities under Grant No. 2018IVA006.

\section{References}

[1] Ayyub BM, Sohn YG, Saadatmanesh H. Prestressed composite girders under positive moment. ASCE Journal of Structural Engineering 1990; 116(11): 2931-2951.

[2] Ayyub BM, Sohn YG, Saadatmanesh H. Prestressed composite girders. I: Experimental study for negative moment. ASCE Journal of Structural Engineering 1992; 118(10): 2743-2762.

[3] Ayyub BM, Sohn YG, Saadatmanesh H. Prestressed composite girders. II: Analytical study for negative moment. ASCE Journal of Structural Engineering 1992; 118(10): 2763-2783.

[4] Dall'Asta A, Zona A. Finite element model for externally prestressed composite beams with deformable connection. ASCE Journal of Structural Engineering 2005; 131(5): 706-714.

[5] Zona A, Ragni L, Dall'Asta A. Simplified method for the analysis of externally prestressed steel-concrete composite beams. Journal of Constructional Steel Research 2009; 65: 308-313.

[6] Nie J, Tao M, Cai CS, Li S. Analytical and numerical modeling of prestressed continuous steel-concrete composite beams. ASCE Journal of Structural 
Engineering 2011; 137(12): 1405-1418.

[7] Lou T, Lopes SMR, Lopes AV. Numerical modeling of externally prestressed steel-concrete composite beams. Journal of Constructional Steel Research 2016; 121: $229-236$.

[8] Moscoso AM, Tamayo JLP, Morsch IB. Numerical simulation of external pre-stressed steel-concrete composite beams. Computers and Concrete 2017; 19(2): 191-201.

[9] Chen S, Gu P. Load carrying capacity of composite beams prestressed with external tendons under positive moment. Journal of Constructional Steel Research 2005; 61: 515-530.

[10] Zhang N, Fu CC. Experimental and theoretical studies on composite steel-concrete box beams with external tendons. Engineering Structures 2009; 31: $275-283$.

[11] Uy B, Craine S. Static Flexural behaviour of externally post-tensioned steel-concrete composite beams. Advances in Structural Engineering 2004; 7(1): $1-20$.

[12] Xue WC, Ding M, He C, Li J. Long-term behavior of prestressed composite beams at service loads for one year. ASCE Journal of Structural Engineering 2008; 134(6): 930-937.

[13] Chen S, Jia Y. Numerical investigation of inelastic buckling of steel-concrete composite beams prestressed with external tendons. Thin-Walled Structures 2010; 48: $233-242$. 
[14] El-Zohairy A, Salim H, Shaaban H, Mustafa S, El-Shihy A. Finite-element modeling of externally posttensioned composite beams. ASCE Journal of Bridge Engineering 2015; 20(12), 04015018.

[15] El-Zohairy A, Salim H. Parametric study for post-tensioned composite beams with external tendons. Advances in Structural Engineering 2017; 20(10): 1433-1450.

[16] Chen SM. Experimental study of prestressed steel-concrete composite beams with external tendons for negative moments. Journal of Constructional Steel Research 2005; 61(12): 1613-1630.

[17] Nie J, Tao M, Cai CS, Li S. Deformation analysis of prestressed continuous steel-concrete composite beams. ASCE Journal of Structural Engineering 2009; 135(11): 1377-1389.

[18] Chen S, Wang X, Jia Y. A comparative study of continuous steel-concrete composite beams prestressed with external tendons: Experimental investigation. Journal of Constructional Steel Research 2009; 65: 1480-1489.

[19] Chen S, Jia Y, Wang X. Experimental study of moment redistribution and load carrying capacity of externally prestressed continuous composite beams. Structural Engineering and Mechanics 2009; 31(5): 605-619.

[20] Lou T, Karavasilis TL. Numerical assessment of the nonlinear behavior of continuous prestressed steel-concrete composite beams. Engineering Structures 2019; 190: 116-127.

[21] Zhao XL, Zhang L. State-of-the-art review on FRP strengthened steel structures. 
Engineering Structures 2007; 29(8): 1808-1823.

[22] Teng JG, Yu T, Fernando D. Strengthening of steel structures with fiber-reinforced polymer composites. Journal of Constructional Steel Research 2012; 78: 131-143.

[23] Siwowski TW, Siwowska P. Experimental study on CFRP-strengthened steel beams. Composites Part B: Engineering 2018; 149: 12-21.

[24] Al-Saidy AH, Klaiber FW, Wipf TJ. Strengthening of steel-concrete composite girders using carbon fiber reinforced polymer plates. Construction and Building Materials 2007; 21: 295-302.

[25] Fam A, MacDougall C, Shaat A. Upgrading steel-concrete composite girders and repair of damaged steel beams using bonded CFRP laminates. Thin-Walled Structures 2009; 47: 1122-1135

[26] Ragab N, El-Hacha R. Effectiveness of various repair systems for flexural strengthening of steel-concrete composite girders. Proceedings of the 7th International Conference on Short and Medium Span Bridges (SMSB-VII), Montreal, Quebec, Canada, (CD Rom, Paper RR-107); 2006. 11p.

[27] Ragab N, El-Hacha R. Finite element modeling of steel-concrete composite girders strengthened using FRP. Fourth International Conference on FRP Composites in Civil Engineering (CICE2008), Zurich, Switzerland; 22-24 July 2008.

[28] Tavakkolizadeh M, Saadatmanesh H. Strengthening of steel-concrete composite girders using carbon fiber reinforced polymers sheets. ASCE Journal of Structural 
Engineering 2003; 129(1): 30-40.

[29] Hollaway LC, Cadei J. Progress in the technique of upgrading metallic structures with advanced polymer composites. Progress in Structural Engineering and Materials 2002; 4: 131-148.

[30] Shaat A, Schnerch D, Fam A, Rizkalla S. Retrofit of steel structures using Fiber-Reinforced Polymers (FRP): State-of-the-art. Transportation Research Board (TRB) Annual Meeting, Washington, CD-ROM (04-4063); 2004.

[31] ACI committee 440. Prestressing concrete structures with FRP tendons. ACI 440.4R-04, Farmington Hills, MI; 2004.

[32] Schmidt JW, Bennitz A, Taljsten B, Goltermann P, Pedersen H. Mechanical anchorage of FRP tendons - A literature review. Construction and Building Materials 2012; 32: 110-121.

[33] Aly MYE, El-Hacha R. Strength evaluation of steel-concrete composite girders strengthened with prestressed FRP laminates. Second Official Regional Conference of International Institute for FRP in Construction for Asia-Pacific Region, (APFIS 2009), Seoul; 09-11 December 2009.

[34] Zangeneh P, Omran H, El-Hacha R. Numerical simulation of prestressed CFRP plate strengthened steel-concrete composite girders, Proceedings of the 5th International Conference on FRP Composites in Civil Engineering (CICE 2010), Beijing; 2010. p 929-932.

[35] Deng J, Lee MMK, Li S. Flexural strength of steel-concrete composite beams reinforced with a prestressed CFRP plate. Construction and Building Materials 
2011; 25: 379-384.

[36] Deng J, Lee MMK, Huang P. Elastic moment capacity and prestress loss of steel-concrete composite beams strengthened with a prestresssed CFRP plate. First Asia-Pacific Conference on FRP in Structures, Hong Kong; 12-14 December 2007. p 367-371.

[37] Ghafoori E, Motavalli M. Innovative CFRP-prestressing system for strengthening of metallic structures. ASCE Journal of Composites for Construction 2015; 19(6): 04015006.

[38] Bennitz A, Schmidt JW, Nilimaa J, Taljsten B, Goltermann P, Ravn DL. Reinforced concrete T-beams externally prestressed with unbonded carbon fiber-reinforced polymer tendons. ACI Structural Journal 2012; 109(4): 521-530.

[39] Lou T, Lopes SMR, Lopes AV. Effect of linear transformation on nonlinear behavior of continuous prestressed beams with external FRP cables. Engineering Structures 2017; 147: 410-424.

[40] Lou T, Karavasilis TL. Time-dependent assessment and deflection prediction of prestressed concrete beams with unbonded CFRP tendons. Composite Structures 2018; 194: 365-376.

[41] Hognestad E. A study of combined bending and axial load in reinforced concrete members. Bulletin No. 399, University of Illinois Engineering Experiment Station, Urbana, IL; 1951.

[42] Menegotto M, Pinto PE. Method of analysis for cyclically loaded reinforced concrete plane frames. IABSE preliminary report for symposium on resistance 
and ultimate deformability of structures acted on well-defined repeated loads, Lisbon; 1973. p 15-22. 
Table 1. Material properties for PSCC specimens.

\begin{tabular}{|c|c|c|c|c|c|c|c|}
\hline \multirow{3}{*}{ Specimen } & \multicolumn{3}{|c|}{ Concrete } & \multicolumn{2}{c|}{ Steel beam } & \multicolumn{2}{c|}{ Steel tendon } \\
\cline { 2 - 8 } & $f_{c}^{\prime}$ & $f_{t}$ & $E_{c}$ & $f_{y}$ & $E_{s}$ & $f_{p u}$ & $E_{p}$ \\
& $(\mathrm{MPa})$ & $(\mathrm{MPa})$ & $(\mathrm{GPa})$ & $(\mathrm{MPa})$ & $(\mathrm{GPa})$ & $(\mathrm{MPa})$ & $(\mathrm{GPa})$ \\
\hline B & 40 & 4.0 & 35 & 411.6 & 200 & 1860 & 195 \\
\hline PCCB-4 & 24.4 & 2.4 & 31 & 269.8 & 200 & 1860 & 195 \\
\hline
\end{tabular}




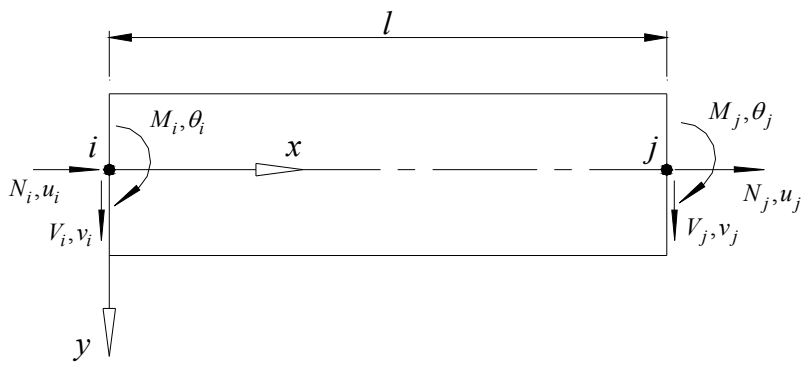

Fig. 1. Beam element. 

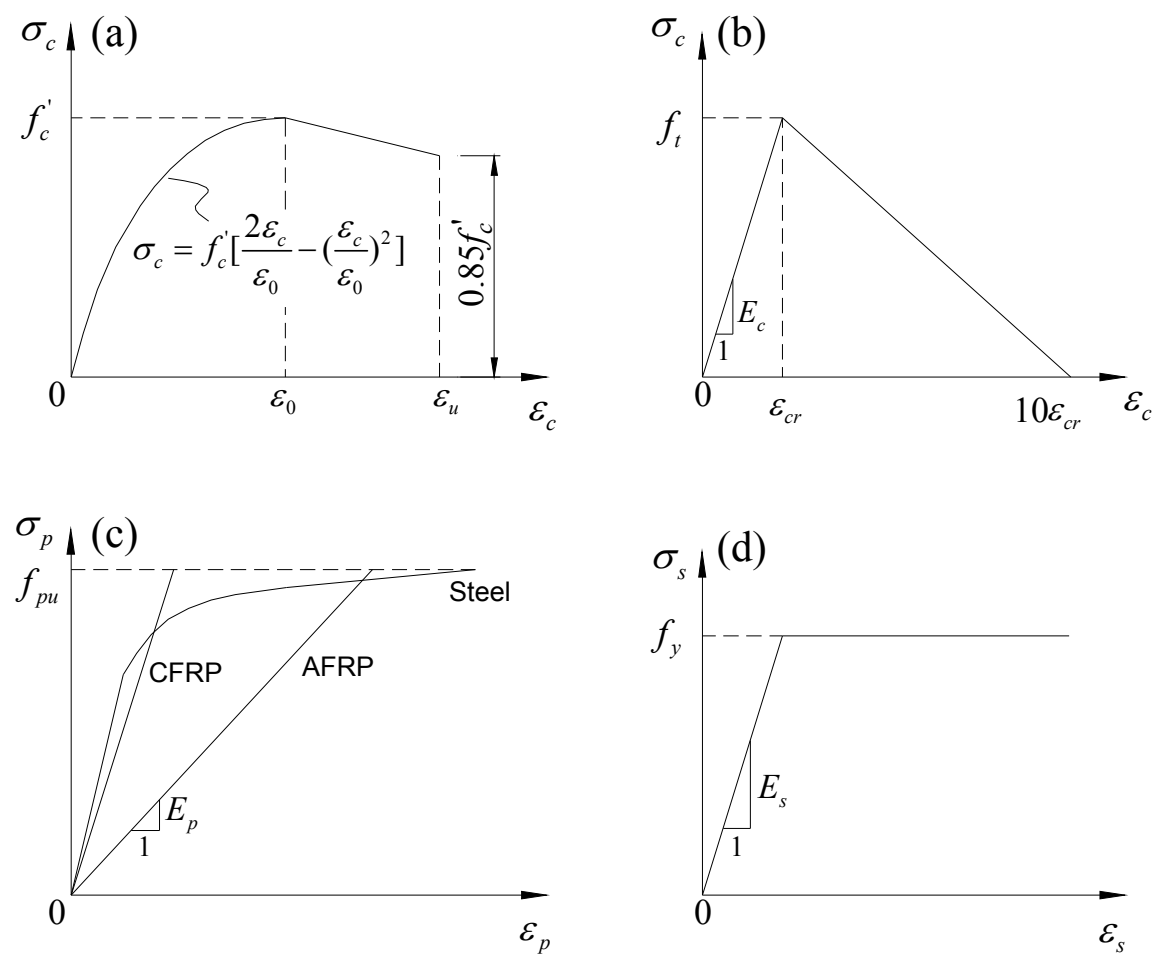

Fig. 2. Stress-strain curves for materials. (a) concrete in compression; (b) concrete in tension; (c) prestressing tendons; (d) steel beam and reinforcing steel. 

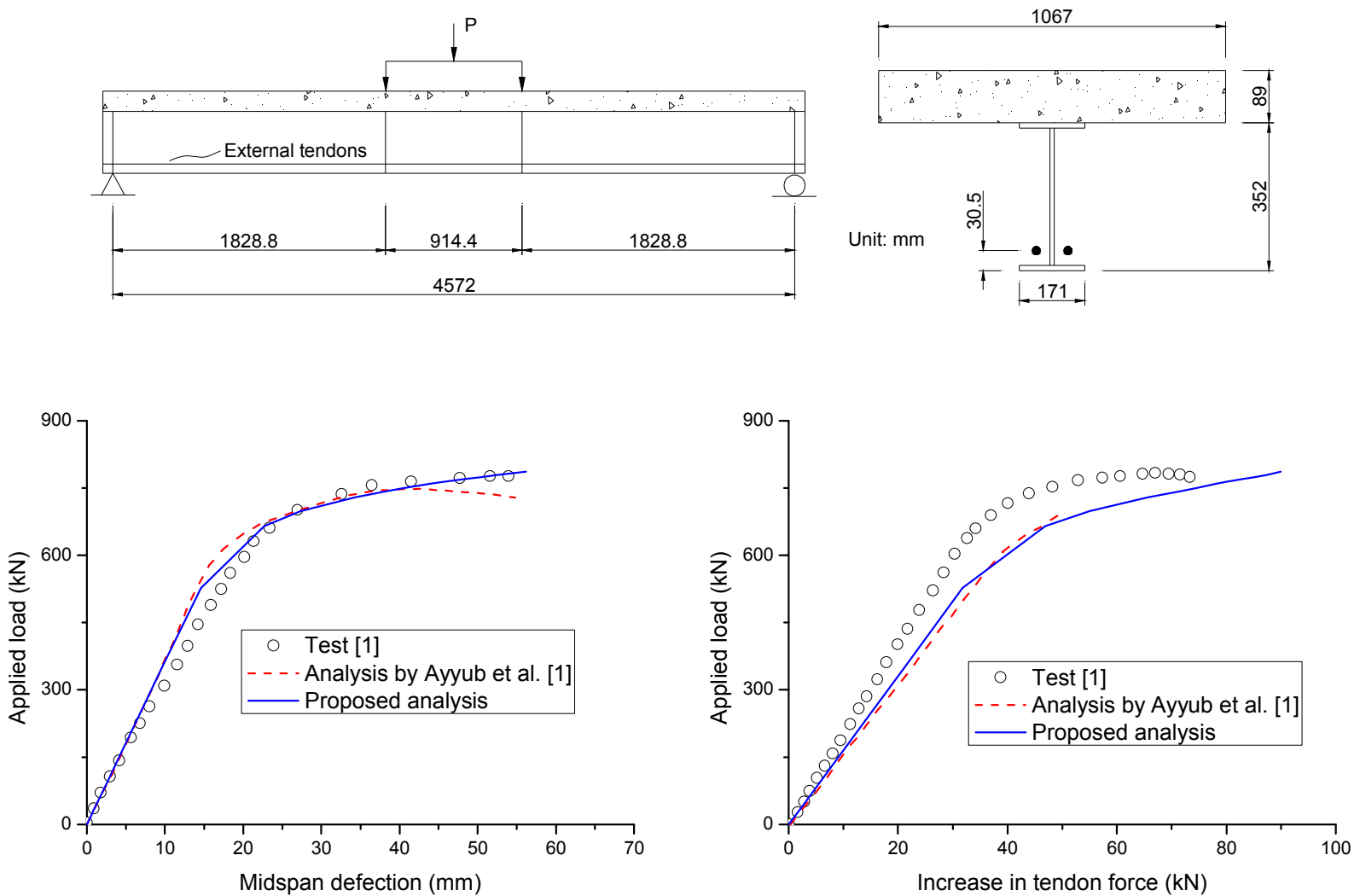

Fig. 3. Comparison between analysis and test results for simply supported PSCC specimen (B). 

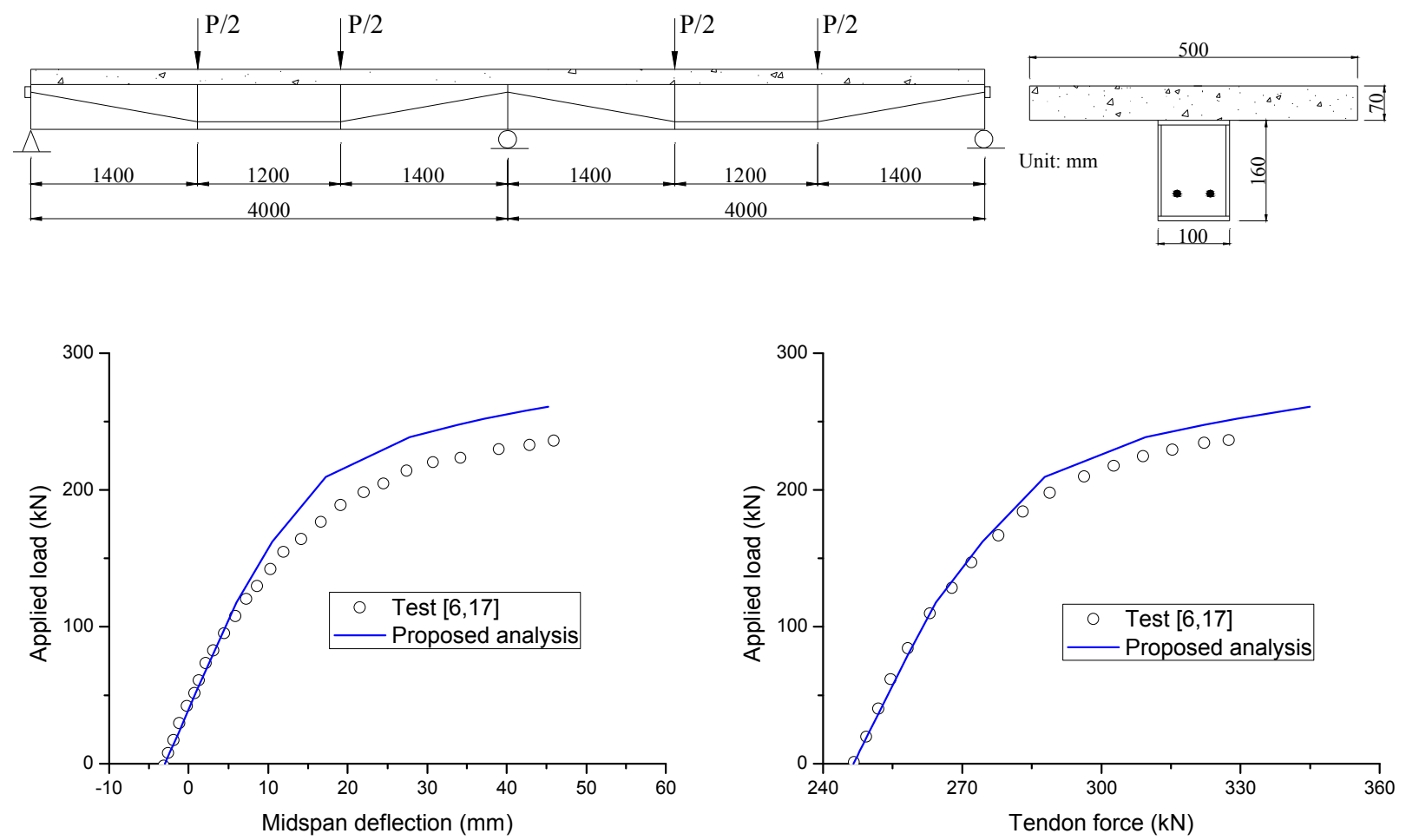

Fig. 4. Comparison between analysis and test results for continuous PSCC specimen (PCCB-4). 

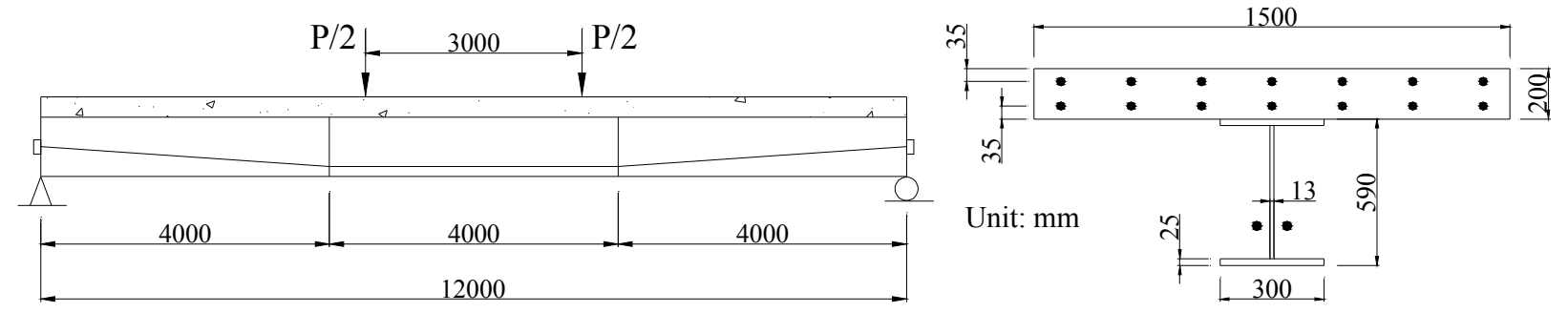

Fig. 5. Simply supported PSCC girders considered in this investigation. 

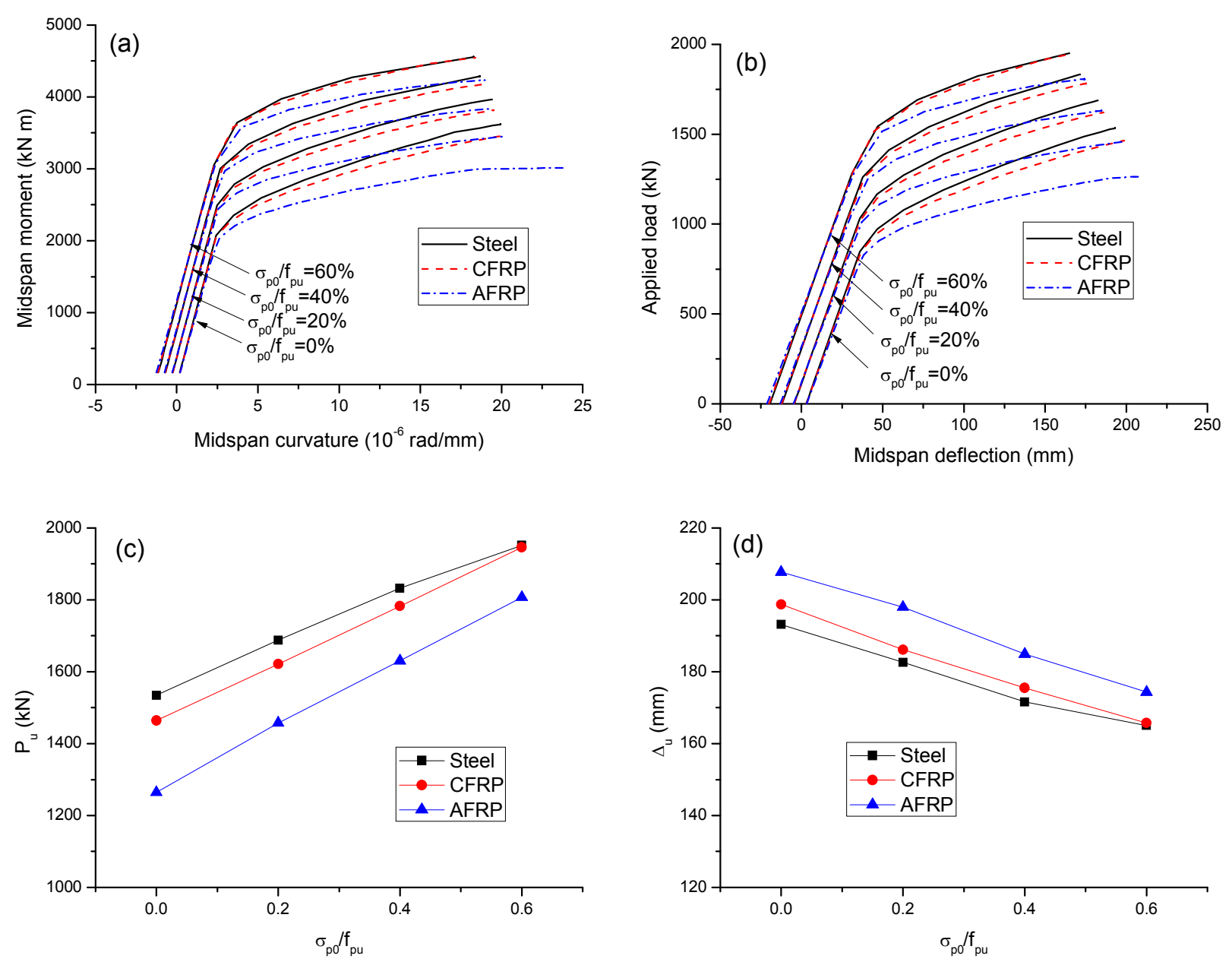

Fig. 6. Load-deformation characteristics. (a) moment-curvature curves; (b) load-deflection curves; (c) variation of ultimate load $\left(P_{u}\right)$ with the prestress level; (d) variation of ultimate deflection $\left(\Delta_{u}\right)$ with the prestress level. 

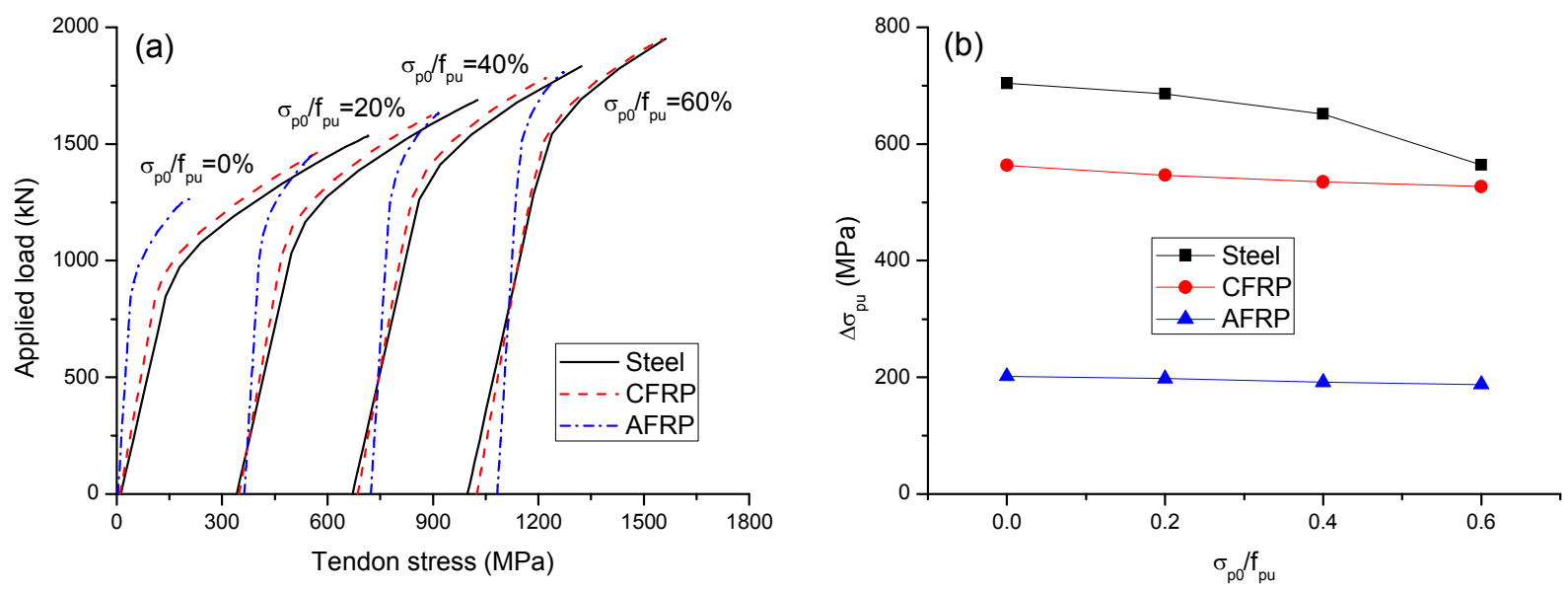

Fig. 7. Stress increase in external tendons. (a) load versus tendon stress curves; (b) variation of ultimate tendon stress increment $\left(\Delta \sigma_{p u}\right)$ with the prestress level. 

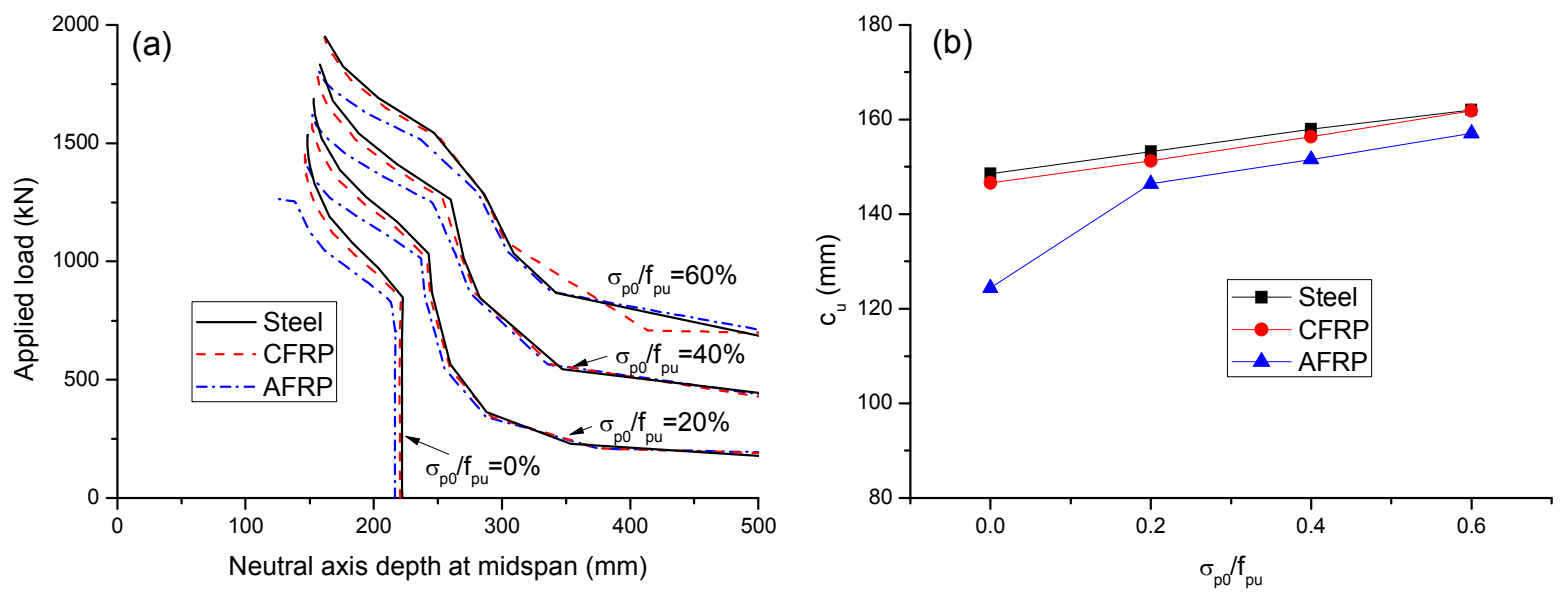

Fig. 8. Neutral axis depth characteristics. (a) load versus neutral axis depth curves; (b) variation of neutral axis depth at ultimate $\left(c_{u}\right)$ with the prestress level. 

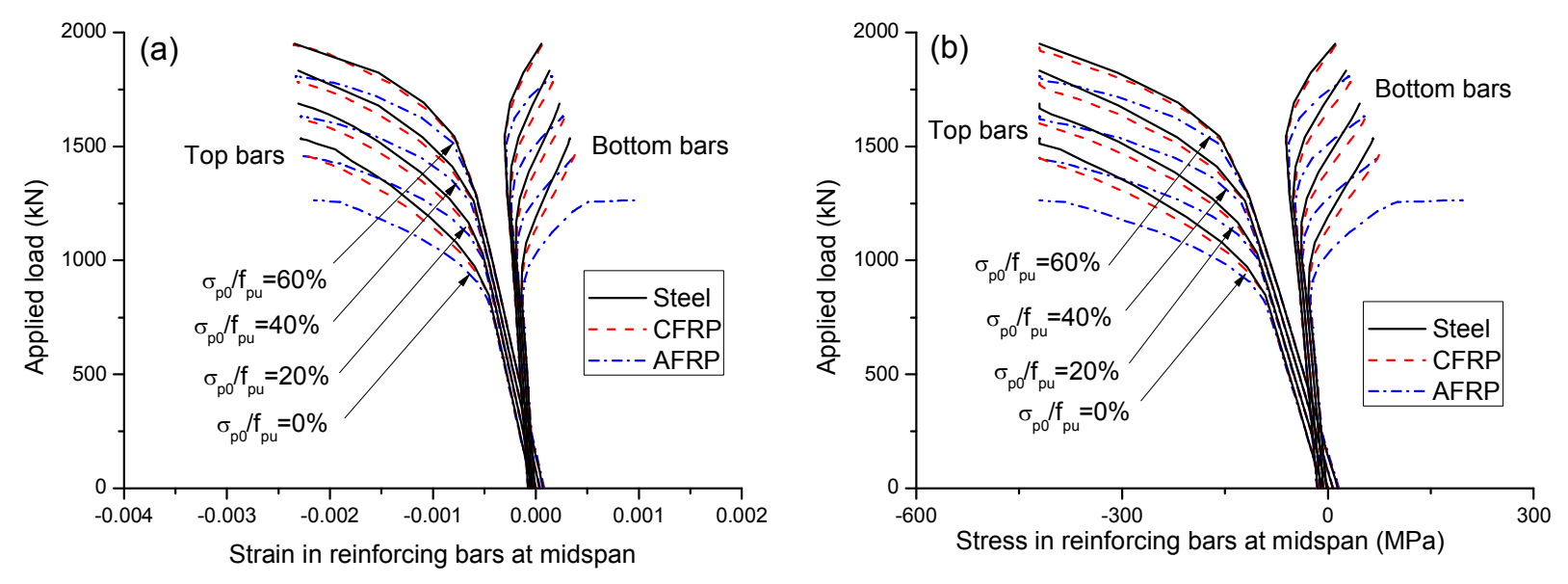

Fig. 9. Strain and stress in reinforcing bars. (a) load versus bar strain curves; (b) load versus bar stress curves. 

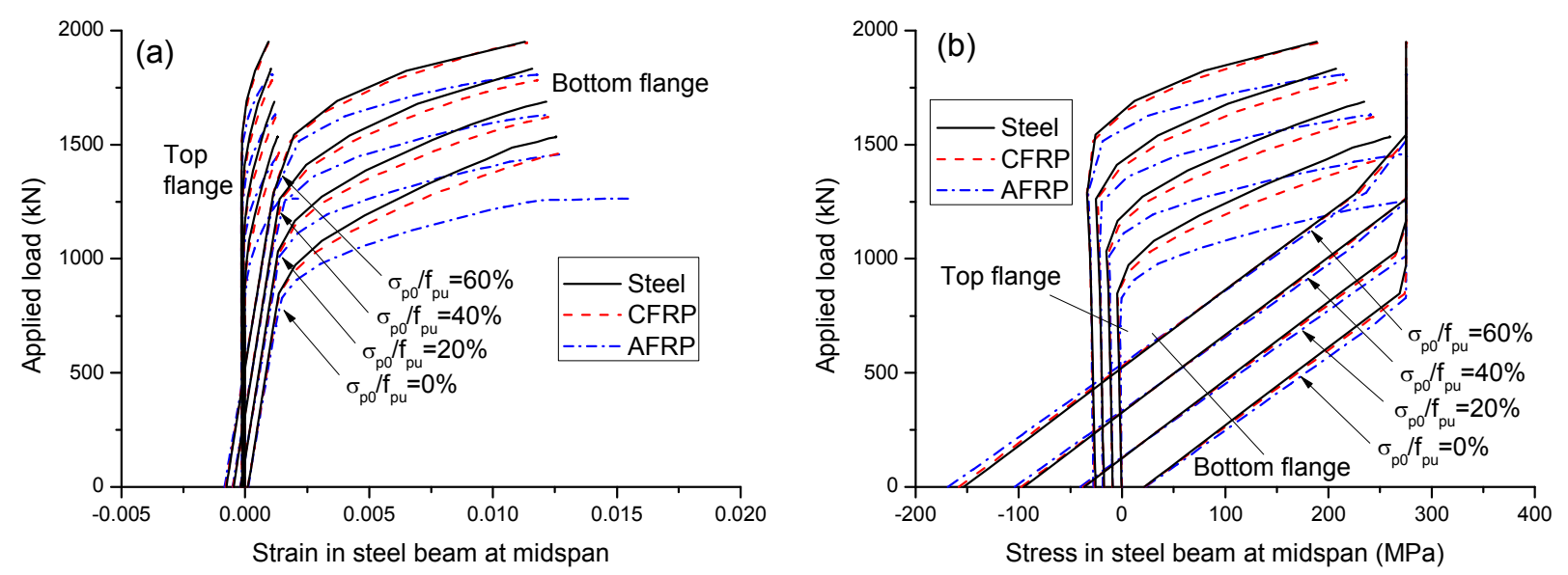

Fig. 10. Strain and stress in steel beam. (a) load versus steel strain curves; (b) load versus steel stress curves. 


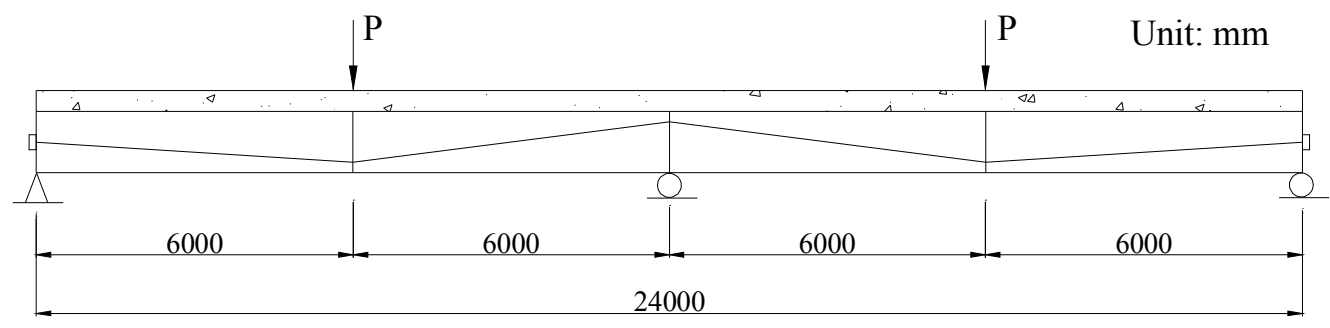

Fig. 11. Continuous PSCC girders considered in this investigation. 

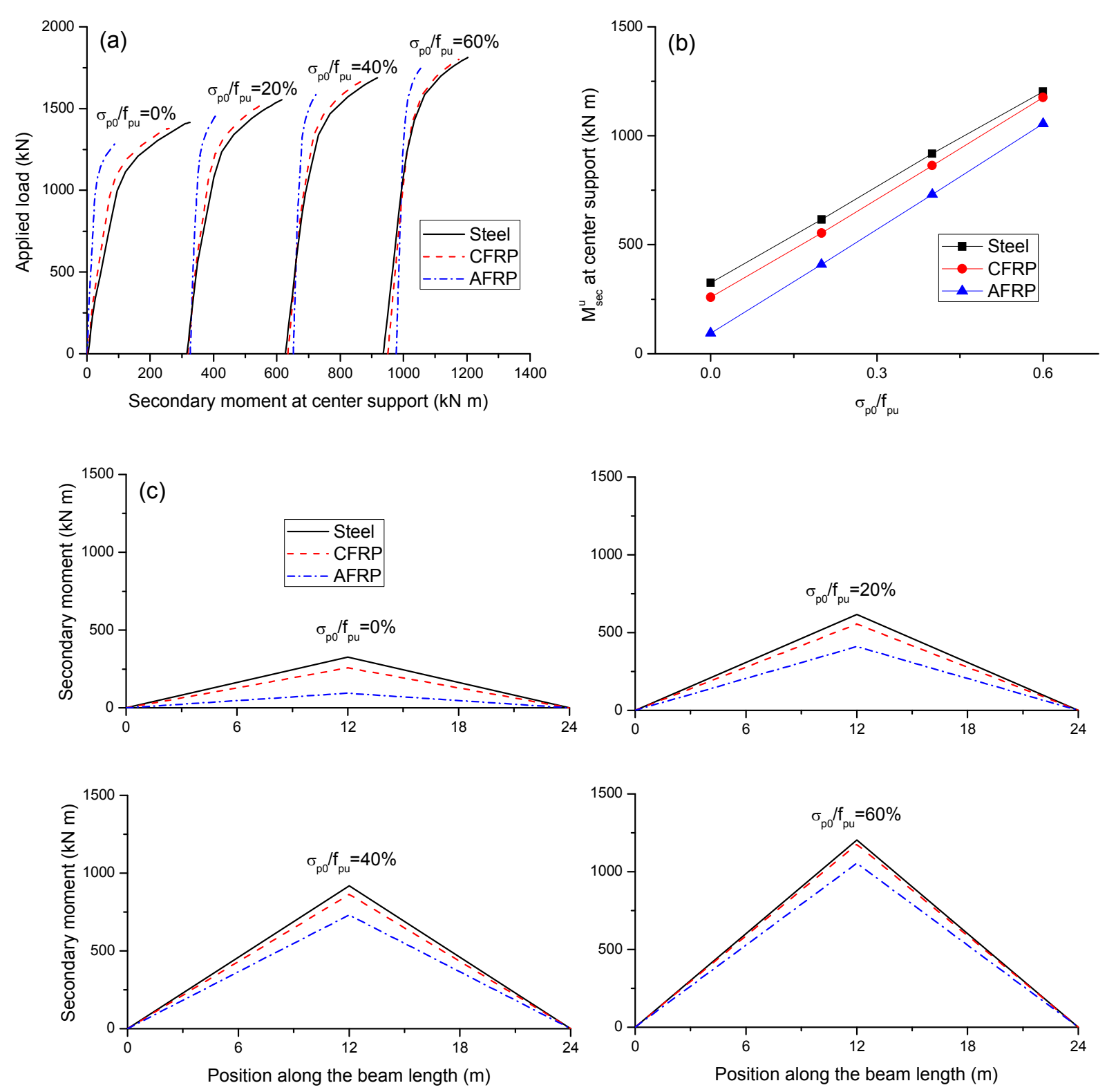

Fig. 12. Secondary moment characteristics for different tendon types and prestress levels. (a) load versus secondary moment curves; (b) variation of secondary moment at ultimate $\left(M_{\mathrm{sec}}^{u}\right)$ with the prestress level. (c) distribution of secondary moments. 

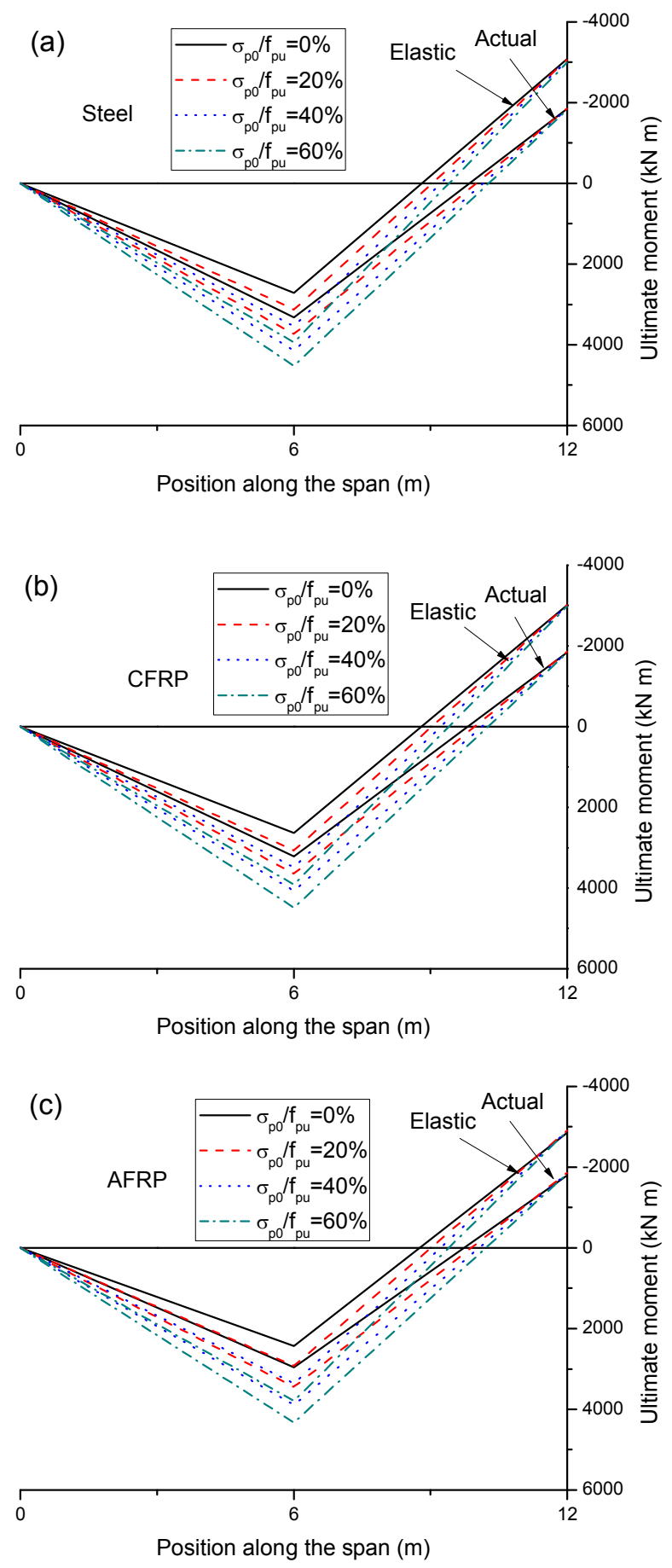

Fig. 13. Moment distribution diagrams for various prestress levels. (a) steel tendons; (b) CFRP tendons; (c) AFRP tendons. 

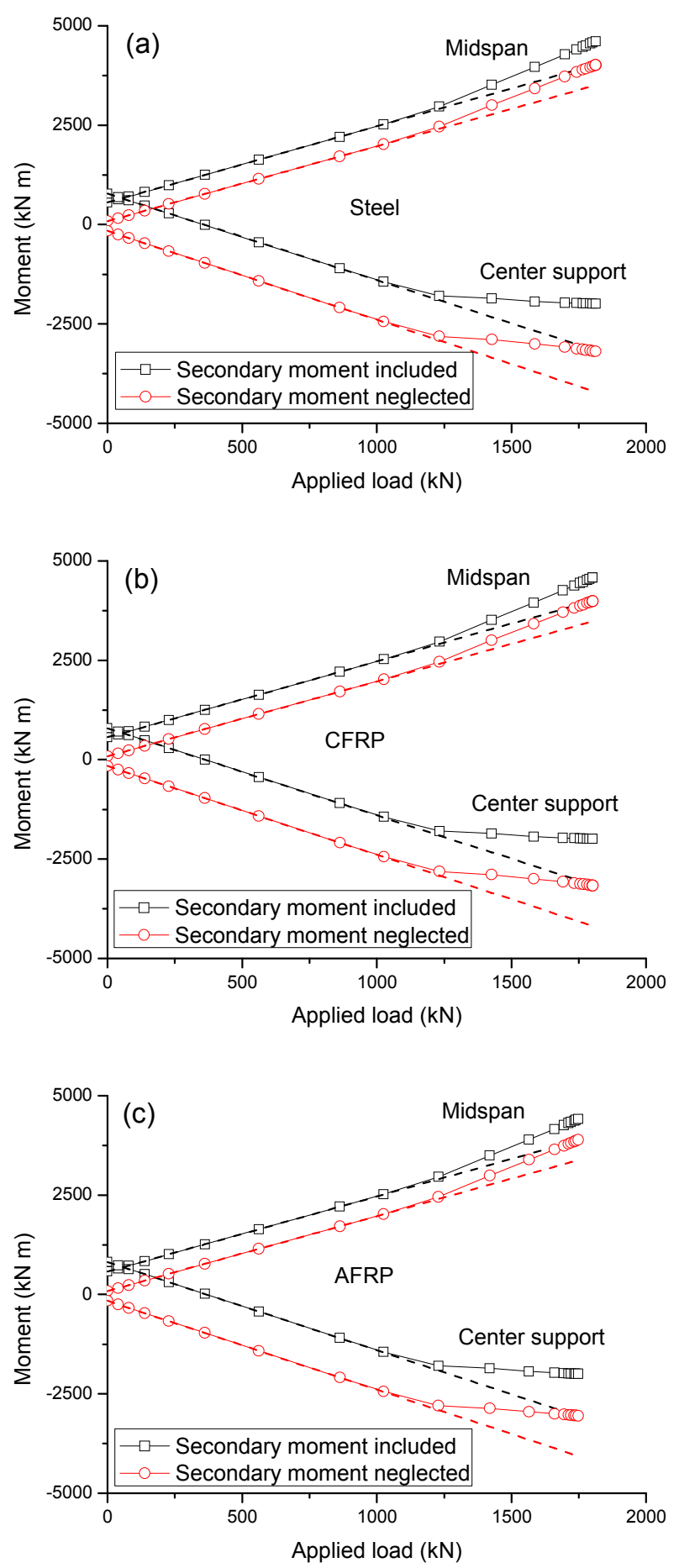

Fig. 14. Load-moment curves for the prestress level of $60 \%$. (a) steel tendons; (b) CFRP tendons; (c) AFRP tendons. 

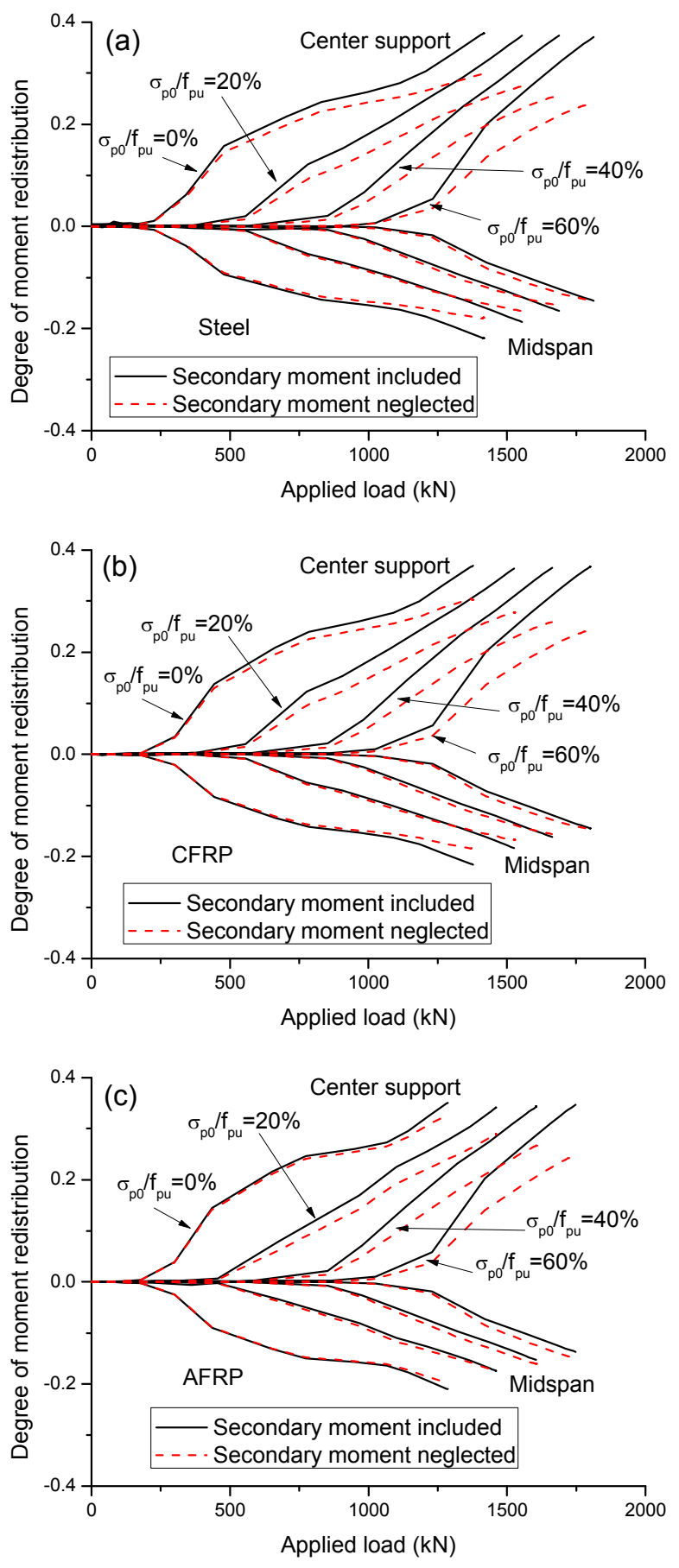

Fig. 15. Load versus degree of moment redistribution curves for various prestress levels. (a) steel tendons; (b) CFRP tendons; (c) AFRP tendons. 

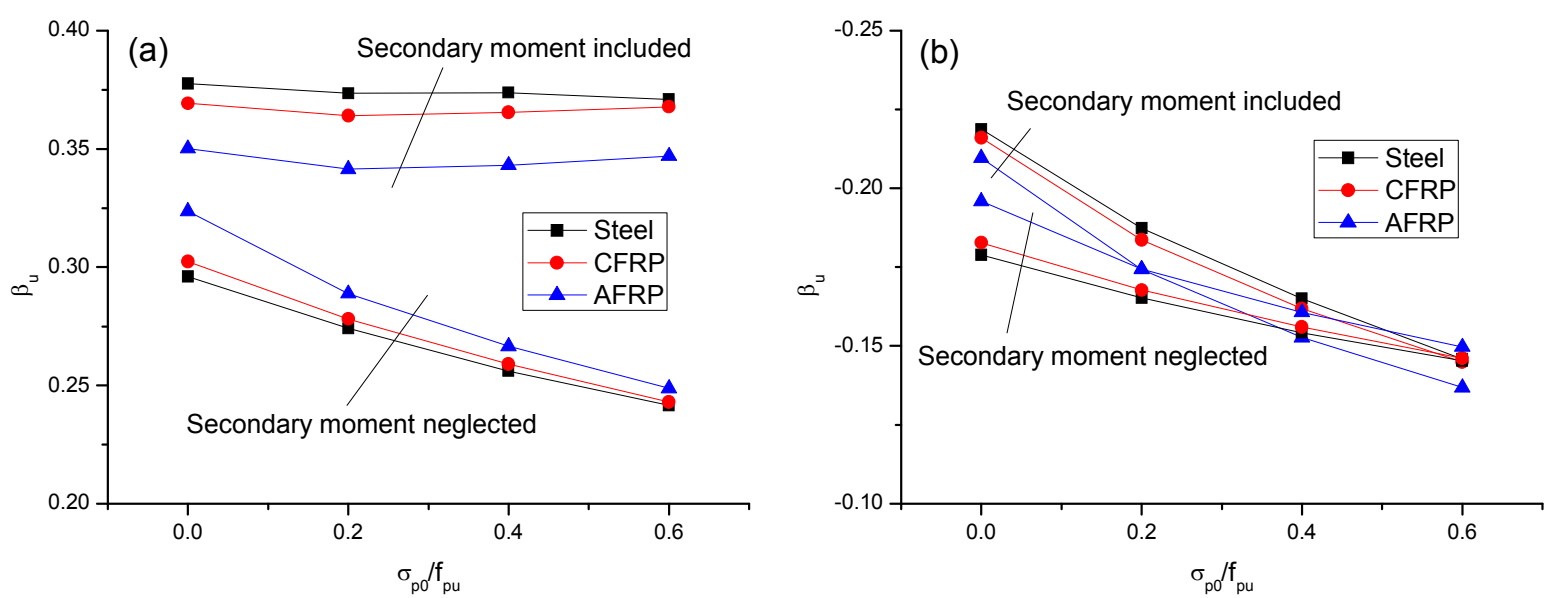

Fig. 16. Variation of moment redistribution at ultimate $\left(\beta_{u}\right)$ with the prestress level.

(a) center support; (b) midspan. 